Bioscientia Medicina: Journal of Biomedicine \&

Translational Research

Journal Homepage: www.bioscmed.com

\title{
The Risk Factors Affecting Disability Level of Lumbar Disc Herniation Melda Yelmaiza ${ }^{1}$, Restu Susanti $^{2 *}$, Syarif Indra ${ }^{2}$
}

${ }^{1}$ Department of Neurology, Faculty of Medicine, Andalas University/Dr. M. Djamil General Hospital, Padang, Indonesia

2 Lecturer Staff of Neurology, Faculty of Medicine, Andalas University/Dr. M. Djamil General Hospital, Padang, Indonesia

\section{A R T I C L E I N F O}

Keywords :

Hernia nucleus pulposus

Lumbar disc herniation

Disability level

Risk factors

\section{*Corresponding author:}

Restu Susanti

E-mail address:

restususanti@yahoo.com

All authors have reviewed and approved the final version of the manuscript.

https://doi.org/10.32539/bsm.v6i1.433

\section{A B S T R A C T}

Background. Lumbar disc herniation (LDH) is a disorder that involves rupture of the annulus fibrosus so that the nucleus pulposus protrudes and compresses the lumbar canal. LDH is the most common cause of lumbar radiculopathy. LDH causes functional disorders in patients, causing disability to carry out daily activities. The purpose of this study was to determine the risk factors that influence the degree of disability in lumbar nucleus pulposus herniation.

Methods. Analytical research with a consecutive cross-sectional study approach in patients with lumbar LDH at the Neurology Outpatient Clinic, Dr. M. Djamil General Hospital Padang from March to November 2021. The risk factors assessed were age, gender, occupation, length of illness, and body mass index (BMI). The measurement of the degree of disability uses the Oswestry disability index (ODI) score. The relationship between risk factors and the degree of disability was analyzed using chisquare test. Differences in the mean age of groups with mild and moderate degrees of disability using unpaired t-test.

Results. 40 subjects met the inclusion and exclusion criteria. Mean age $57 \pm 10,976$ years, male and female ratio 1:2, work with heavy lifting activities was found in $70 \%$ of subjects, duration of suffering from LDH more than one year in $60 \%$ of subjects. BMI overweight and obesity as many as $77.5 \%$ subjects. As many as $60 \%$ of the subjects experienced mild to moderate degrees of disability. There is a difference in the average age of the subjects with mild to moderate degree of disability with a severe degree of $\mathrm{p}$-value of 0.044 . There was no significant relationship between gender $(p=0.054)$, occupation $(p=0.398)$, length of illness $(p=0.503)$ and body mass index $(\mathrm{p}=0.757)$, and the degree of disability.

Conclusion. The degree of disability in patients with LDH is influenced by age.

Meanwhile, gender, occupation, length of illness and body mass index were not significantly related to the degree of disability in patients.

\section{Introduction}

Lumbar disc herniation (LDH) is a condition where there is a protrusion of the intervertebral disc, which causes pressure on the spinal cord, which can cause symptoms of pain and interfere with activities. Risk factors for hernia nucleus pulposus were gender, age, occupation, body mass index, and history of trauma. ${ }^{1}$ Symptom of low back pain caused by LDH is radicular pain. The back pain that is felt will cause the patient to experience an inability or disability, resulting in functional limitations in daily activities. Patients with low back pain often complain of decreased or even inability to carry out daily activities. The impact of pain and limited movement experienced can be described as a disability problem that affects physical function. In other words, patients who have a high level of disability will have more significant physical limitations. 2,3

Lumbar disc herniation is the leading cause of disability in the world. The degree of disability in patients with LDH is of great importance to clinical practice and research. The Oswestry disability index (ODI) is one of the most commonly used scales to assess the disability associated with LDH. ODI is a score used to measure the level of disability of low back pain patients. The level of disability is divided into very mild, mild, moderate, severe, and very severe. ${ }^{4}$ Approximately 90-97\% of LDH occurs at the L4-L5 and L5-S1 levels. Less than 5\% of all disc herniations occur in the upper lumbar vertebral segment found more in men. ${ }^{5}$ This study aims to determine the risk factors that influence the degree of disability in lumbar nucleus 
pulposus herniation.

\section{Methods}

This study is analytical research with a consecutive cross-sectional study approach in patients with lumbar disc herniation (LDH). It was conducted at the Neurology Outpatient Clinic, Dr. M. Djamil Padang General Hospital, from March to November 2021. All clinical procedures were carried out following the Declaration of Helsinki, and the approval of the Research Ethics Council, Faculty of Medicine, Andalas University, with ethical approval number 35/KEPK/2021. The inclusion criteria for lumbar LDH were established from the history, neurological physical examination, and lumbar MRI. The exclusion criteria were patients aged below 20 years old and more than 80 years old. The essential characteristics as risk factors, namely age, gender, occupation, length of illness, and body mass index, were obtained from interviews with patients. The measurement of the degree of disability uses the Oswestry Disability Index (ODI) score. The ODI has 10 question items about daily activities that may be disrupted or hindered in patients with low back pain. The ODI measurement method consists of several primary factors: pain intensity, selfcare, lifting, walking, sitting, standing, sleeping, sexual activities, social life, and recreation. 6 Statistical analysis in the form of descriptive data from risk factors. The relationship between risk factors and the degree of disability was analyzed using the chi-square test. Differences in the mean age of groups with mild and moderate degrees of disability using unpaired ttest.

\section{Results}

Forty subjects met the inclusion and exclusion criteria. The basic characteristics of the subjects were the mean age of $57 \pm 10,976$ years, the ratio of men and women 1:2, work with heavy lifting activities was found in $70 \%$ of the subjects, the duration of suffering from LDH was more than one year as many as $60 \%$ of the subjects. With a body mass index of overweight and obesity in $77.5 \%$ of the subjects.

Table 1. Characteristic of participants

\begin{tabular}{|c|c|c|c|c|}
\hline \multirow[t]{2}{*}{ Variable } & \multicolumn{2}{|c|}{ Disabilities level of LDH } & \multirow[t]{2}{*}{ OR } & \multirow[t]{2}{*}{ Pvalue } \\
\hline & Mild-moderate & Severe & & \\
\hline Age, mean+SD & $58.71 \pm 10.683$ & $51.63+10.301$ & & 0.044 * \\
\hline $\begin{array}{l}\text { Gender } \\
\text { Male, } \mathrm{n} \\
\text { Female, } \mathrm{n}\end{array}$ & $\begin{array}{c}5 \\
19\end{array}$ & $\begin{array}{l}8 \\
8\end{array}$ & 0.263 & $0.054 \#$ \\
\hline $\begin{array}{l}\text { Occupation } \\
\text { Long sitting activities, n } \\
\text { Heavy work lift, n }\end{array}$ & $\begin{array}{c}6 \\
18\end{array}$ & $\begin{array}{c}6 \\
10\end{array}$ & 0.556 & 0.398 \# \\
\hline $\begin{array}{l}\text { Length of illness } \\
<6 \text { months, } \mathrm{n} \\
6 \text { months }-1 \text { years, } \mathrm{n} \\
1 \text { years, } \mathrm{n}\end{array}$ & $\begin{array}{c}4 \\
4 \\
16\end{array}$ & $\begin{array}{l}5 \\
3 \\
8\end{array}$ & & 0.503 \# \\
\hline $\begin{array}{l}\text { Body mass index } \\
\text { Normal, } \mathrm{n} \\
\text { Abnormal, } \mathrm{n}\end{array}$ & $\begin{array}{c}5 \\
19\end{array}$ & $\begin{array}{c}4 \\
12\end{array}$ & 0.789 & $0.757 \#$ \\
\hline
\end{tabular}

" unpaired T test, \# Chi square test

A total of $60 \%$ of subjects experienced mild to moderate degree of disability, and $40 \%$ of subjects experienced a severe degree of disability. There is a difference in the average age of subjects with mild to moderate degrees of disability with severe degrees with $\mathrm{p}$-value $=0.044$. There was no significant relationship between gender, occupation, length of illness, and body mass index with the degree of disability (p 0.054; 0.398; $0.503 ; 0.757)$. 


\section{Discussion}

Low back pain (LBP) is pain, muscle tension, or stiffness localized between the lower rib margin and the inferior gluteal fold, with or without radiating to the thigh and leg (sciatica). ${ }^{7}$ One of the causes of lower back pain is the degenerative process of hernia nucleus pulposus (LDH). ${ }^{8}$ Hernia nucleus pulposus is a state where the protrusion of the intervertebral disc causes pressure on the spinal cord that can cause pain and interfere with the activity. Risk factors for lumbar disc herniation (LDH) are gender, age, occupation, body mass index, and history of trauma. ${ }^{1}$

The symptoms experienced by the patient are determined by the location of the herniated intervertebral disc. Cardinal symptoms found in patients with lumbar LDH are back pain accompanied by pain radiating to the legs; it is the most common symptom in patients with LDH. Young adults are often affected by LDH. The pain increases when the patient sits, sneezes, coughs and is relieved by standing or lying down, with a positive Laseque sign in a patient with lumbar LDH. The most commonly affected areas are L4-L5, followed by L5-S1 areas. Symptoms are usually unilateral and cause monoradicular pain. ${ }^{9}$

This study investigated the relationship between risk factors for hernia nucleus pulposus and the degree of functional impairment based on the ODI score. Our study found that most LDH patients were women. The ratio of men to women is $32.5 \%$ : $67.5 \%$ (1:2). This may also be because more female patients visited than male patients at the study time. This is similar to the study by Kim et al. in 2015 that women had a 50.61\% risk factor for developing lumbar LDH compared to men. 10 Women are considered to feel more pain than men and are more aware of pain. Other factors are hormonal and genetic, affecting the degeneration of the vertebral bones in women. The location most often affected by lumbar LDH is L4-L5, which is $72.4 \%$, because L4-L5 is not attached to the pelvis, so the response to muscle imbalance in the lumbopelvic can cause nerve irritation in the vertebral column. ${ }^{11,12,13}$

In contrast, a study in 2012 by Pinzon showed that the ratio of the incidence of $\mathrm{LDH}$ in men compared to women was 2:1.11 Previous study by Wong (2006) stated the similar results and men suffer from LDH more than women. It is because men are involved in heavy work than women.11,12 From the results of this study, there was no significant relationship between gender and the degree of functional impairment in patients with lumbar LDH who went to Dr. M. Djamil General Hospital Padang.

The results of examining the degree of disability and function using the ODI questionnaire found that the average age of $\mathrm{LDH}$ patients with mild-moderate functional impairment was $58.71 \pm 10.683$ years and $51.63 \pm 10.301$ years. The previous study by Jordan (2008) showed that the highest prevalence of LDH occurred in the 30-50 year age group. ${ }^{14}$ Another study by Naufal (2013) stated that LDH most often occurred in the $40-60$ year age group at $59.6 \%$, followed by the 20-39 year age group at 40.4\%.15 The increasing prevalence of $\mathrm{LDH}$ is caused by spinal degeneration due to changes in bone formation that occur at the age of 40-70 years. Changes in the formation or structure of the spine cause the vertebral column to begin to undergo structural changes, resulting in the vertebral bone structure becoming stiffer. The density of the nucleus pulposus decreases, changes in the composition of the intervertebral disc, thereby facilitating inflammation and triggering low back pain. ${ }^{16,17}$

According to Stafford et al. 2007, occupation is also a risk factor for the occurrence of lumbar LDH. 18 The types of work varied, namely farmers, nurses, teachers, traders, and several other types of work. In this study, the types of work are categorized into jobs that lift heavy loads and jobs with long sitting activities. In this study, lumbar LDH occurred more in patients who worked lifting heavy weights than those who were active in the office (long sitting activities) with a ratio of 70\%: 30\%. This is consistent with a study by Stafford et al. (2007) that workers with strenuous activities such as carpenters (OR 1.7) and machine operators (OR: 1.6) were shown to be more likely to experience lumbar LDH compared to office workers who were sedentary. 18

Our study showed no significant relationship and influence between physical workload and disability level ( $p$-value $=0.398$ ). This is because the level of disability is a complex factor that is not only influenced by one dominant factor, so it is difficult to explain the 
primary cause. In addition, the position when working also significantly affects the occurrence of lumbar LDH, for example, uncomfortable position or a bent state while working, the position of the hands above the shoulders during work, this will also affect the incidence lumbar LDH. Working as a driver can also be a risk factor for $\mathrm{LDH}$ because while driving, there is exposure to vibrations of 4-5 Hz, which may coincide with the spinal resonance frequency when in a sitting position so that it has a direct effect on the mechanical effects of the lumbar disc. 18

A study by Kelsey shows a relationship between work and the incidence of $\mathrm{LDH}$, namely with work related to lifting weights. There is a relationship between the incidence of $\mathrm{LDH}$ with lifting weights of more than $11.3 \mathrm{~kg}$ with an average of 25 times per day. The same thing was mentioned in previous studies that work that is too heavy or the frequency of lifting objects that exceed the tolerance limit can cause trauma to the lumbar by $53 \% .19$

This study found that most patients (60\%) had an onset of more than one year, $22.5 \%$ with onset between 6 months to 1 year, and $17.5 \%$ with onset less than six months. Research by Rihn et al. stated that the longer a person suffers from $\mathrm{LDH}$ is directly proportional to the degree of disability in the patient. ${ }^{20}$ Meanwhile, the relative advantage obtained from surgical therapy compared to medical therapy is not affected by the length of time a person suffers from LDH. ${ }^{20}$ From the data analysis conducted in this study, it was found that there was no significant relationship between the length of time a person had suffered from $\mathrm{LDH}$ and the degree of disability calculated using the ODI score. This may be caused by various factors, one of which is the number/area of the affected segment. 5

In this study, it was found that most research subjects had an excessive or abnormal body mass index (overweight and obese), which was $77.5 \%$. According to Tao et al., a higher body mass index value (overweight or obese) has a risk of causing lumbar LDH. ${ }^{21}$ In this study, no significant relationship was found between body mass index and the degree of disability in LDH patients as measured using the ODI score (p-value 0.757). 5 Excess weight, especially the extra weight in the abdominal area, can cause pressure in that area. Previous studies have shown a relationship between excessive BMI and low back pain caused by herniated nucleus pulposus.22,23 Moreover, a clinically-based prospective cross-sectional study in Enugu, Nigeria, stated that the incidence of lumbar LDH at all levels was not affected by body mass index. 5

A study in California and Mexico by Mateos Valenzuela et al. found four components of body composition: the degree of obesity, visceral fat area, body mass index, and abdominal circumference associated with the incidence of lumbar LDH. ${ }^{24}$ Lumbar nucleus pulposus herniation is also associated with the distribution of body adiposity. Visceral fat area and abdominal circumference are risk factors for $\mathrm{LDH}$ in addition to the previously known risk factors, namely age, mechanics, and genetic factors. These risk factors can be modified by adjusting the diet and physical exercise program to prevent the incidence of lumbar LDH related to this. ${ }^{24}$ In Fithri's study in 2017, LDH mainly occurred at the age above 42 years $(74.3 \%)$, more often in women (62.2\%), housewife work (32.4\%), BMI overweight $(38.6 \%)$, and patients with minor trauma (13.5\%). 25

\section{Conclusion}

Risk factors for lumbar LDH include age, gender, occupation, length of illness, and body mass index. Not all of these risk factors are directly proportional to the degree of disability in patients with lumbar LDH. In this study, age was significantly associated with disability in patients with Lumbar LDH. Meanwhile, gender, occupation, length of illness, and body mass index were not significantly related to the degree of disability in patients. This is influenced by the possibility of being influenced by several other factors.

\section{References}

1. Zielinska N, Podgorski M, Haładaj R, Polguj M, Olewnik $€$. Risk factors of intervertebral disc pathology-a point of view formerly and today: A review. J Clin Med. 2021; 10(3): 1-18.

2. Taruli A. Back pain, myelopathy and radiculopaty. Neurology. 2016. $2^{\text {nd }}$ eds. Harvard Medical School: Boston.

3. Akuthota V, Marshall B, Boimbo S, Osborne M, 
Garvan CS, Garvan GJ, et al. Clinical course of motor deficits from lumbosacral radiculopathy due to disk herniation. Phys Med Rehab J. 2019; 11: 807-14.

4. Lee CP, Fu TS, Liu CY, Hung CI. Psychometric evaluation of the oswestry disability index in patients with chronic low back pain: factor and Mokken analyses. Health Qual Life Outcomes. 2017; 15(1): 1-7.

5. Anyanwu GE, Ekwunife RT, Lyidobi EC, Nwadinigwe CU, Ekwedigwe HC, Agu AU et al. Epidemiology of lumbar disc herniations in adults with low back pain in Enugu, Nigeria. Int J Res Orthop. 2020; 6: 1-6.

6. Wahyudin. Modified Oswestry low back pain disability questionnaire (ODI) [In Indonesian]. Department of Physiotherapy. Universitas Esa Unggul: Jakarta. 15-17.

7. Harris S, Wiratman W, Zairinal R. Low back pain in Neurology textbook [In Indonesian]. 2017. 1 $1^{\text {st }}$ edition.

8. Schroeder GD, Guyre CA, Vaccaro AR. The epidemiology and pathophysiology of lumbar disc herniations. Elsevier. 2015.

9. Alberstone CD, Benzel EC, Najm IM, Steinmetz MP. Nerve roots and spinal nerves. Anatomic Basis of Neurologic Disease. 2009. Thieme: New York.

10. Kim et al. The incidence and risk factors for lumbar or sciatic scoliosis in lumbar disk herniation and the outcome after percutaneous endoscopic discectomy. Seoul Univ Col Med. 2015; 18(1): 555-64.

11. Pinzon R. Clinical profile of low back pain patients because of hernia nucleus pulposus (HNP). Department of Neurology. Bethesda Hospital. 2012; 39(10): 1-3

12. Wong DA, Transfeldt E, Macnab I. Macnab's backache. 2006. 4th eds. Lippincott Williams \& Wilkins: Philadelphia.

13. Amin RM, Andrade NS, Neuman BJ. Lumbar disc herniation. Curr Rev Musculoskelet Med. 2017; 10(4): 507-16.

14. Jordan J, Konstantinon K, O’Dowd J. Herniated lumbar disc. BMJ Publishing Group
Ltd.

15. Naufal R. Relationship between ischialgia intensity and disability in daily activities of hernia nucleus pulposus (HNP) patients in Dr Moewardi General Hospital, Surakarta [In Indonesian]. Department of Neurology. Dr Moewardi General Hospital. 2013: 11-12.

16. Nugroho IA, Marchianti ACN, Hermansyah Y. The effect of physical workload on disability level of lower back pain patients in $\mathrm{dr}$. Soebandi Hospital. J Pustaka Kesehatan [Internet]. 2017; 5(2): 316-22.

17. Wu $\mathrm{Q}$. Intervertebral disc aging, degeneration, and associated potential molecular mechanisms. J Head Neck Spine Surg. 2017; 1: $1-5$.

18. Stafford MA, Peng P, Hill DA. Sciatica: a review of history, epidemiology, pathogenesis, and the role of epidural steroid injection in management. Br J Anaesthesia. 2007; 99(4): 461-73.

19. Kelsey J.L. Demographic characteristics of persons with acute herniated lumbar intervertebral disc. J Chorn Disc. 2003; 28(1): 37-50.

20. Rihn JA, Hilbrand AS, Radcliff K, Kurd M, Lurie J, Blood E, et al. Duration of symptoms resulting from lumbar disc herniation: effect on treatment outcomes. J Bone Joint Surg Am. 2011; 93(20): 1906-14.

21. Tao S, Gui-liang Z, Zi-ping Z, Chang-qing D. Study on correlation between body mass index and lumbar disc herniation. China J Modern. 2008.

22. Manchikanti L. Epidemiology of low back pain. Pain Psych. 2000; 3(2): 167-92.

23. Samartizs D, Karppinen J, Chan D, Luk KD, Cheung KM. The association of lumbar intervertebral disc degeneration on magnetic resonance imaging with body mass index in overweight and obese adults: A populationbased study. Arth Rheumatism. 2012; 64: 1488-96.

24. Mateos-Valenzuela AG, González-Macías ME, Ahumada-Valdez S, Villa-Angulo C, 
Villa-Angulo R. Risk factors and association of body composition components for lumbar disc herniation in Northwest, Mexico. Sci Rep. 2020; 10: 18479.

25. Fithri A. Description of risk factors in hernia nucleus pulposus in Adam Malik General Hospital in 2015 [In Indonesian]. Available from

repositori.usu.ac.id/handle/123456789/2036

2. 